\title{
Environmental Education for Sustainable Architecture
}

\author{
Dr Sergio Altomonte \\ Department of the Built Environment, Faculty of Engineering, University of Nottingham \\ University Park, NG7 2RD Nottingham, United Kingdom
}

Tel: 44-115-951-3170Ｅ-mail: sergio.altomonte@nottingham.ac.uk

\begin{abstract}
Awareness of the role that buildings play in the current climate crisis poses new onerous tasks for architectural educators and practitioners. The promotion of sustainability in the design of the built environment is a key-factor for addressing the challenges that mankind faces in response to finite resource availability, ecological deterioration and climate alteration. No longer can the global environmental system support fully-serviced carbon-intensive buildings with the energy consumption and $\mathrm{CO}_{2}$ emissions they trigger. In response to these challenges - and considering the swift development of construction methods and techniques in the building industry - nowadays the professional market demands graduates of architectural disciplines endowed with a number of competences that range from creative design and visualization skills up to detailed technical and environmental competence. A new pedagogical methodology has consequently to be developed in order to overcome existing educational and professional barriers and act as a communication platform that facilitates the transfer of knowledge between sustainability-related building sciences and creative design in the architectural curriculum. The aim of this paper is to critically analyze the hindrances to the successful integration of sustainable environmental design in the pedagogy and practice of architecture and introduce a European Action set to promote the comprehensive implementation of environmental sustainability in building design.
\end{abstract}

Keywords: Education, Architecture, Environment, Sustainability, EDUCATE

\section{Introduction}

Buildings are accounted for around half of worldwide energy consumptions, significantly contributing to global warming and the alteration of natural ecosystems, as proved by recent reports (IPCC, 2007a).

In the context of the current climate crisis - and in consideration of the impact that buildings have on the environment (IPCC, 2007b) and the growing ecological awareness required by new regulations concerned with the construction sector (e.g. the European Directive on Energy Performance of Buildings, 2003) - the role of higher education as a means of comprehensively introducing new generations of architects to the principles and practices of sustainable environmental design is becoming highly significant, although this faces a number of pedagogical and professional barriers.

The need to initiate a change in the formation of building practitioners that supports the successful implementation of environmental considerations in the practice of architecture - including issues of climatic design, choice of materials, construction techniques, passive and hybrid strategies, resource efficiency, reduction of impacts, and so on - is mainly triggered by three factors:

- The current building practice has been slow to consistently respond to the demands of enhancing sustainable environmental design within a creative architectural discourse;

- Existing accreditation and qualification criteria established by professional bodies do not succeed in contributing towards the systematic promotion and diffusion of environmental sustainability in the design of buildings;

- University curricula have shown to be relatively ineffective in methodically integrating sustainable environmental design in the education of students of architecture.

The aim of this paper consists in critically analyzing the hindrances to the successful integration of sustainable environmental design in higher education and the practice of architecture and, consequently, recognising some of the efforts and endeavors which are required to facilitate such integration at a global level. In this context, a European Action set to promote the comprehensive implementation of environmental sustainability in building design is presented, together with its research methodology, result indicators and expected outcomes. 


\section{The Architectural Profession}

The architectural profession is recently witnessing a significant resurgence in the request for the integration of passive and hybrid environmental strategies and techniques in building design, in order to mitigate the impacts on the ecosystem and promote the adaptation of built environments to expected climate alterations (IPCC, 2007c).

After several decades where - following a highly-compartmented educational system - the responsibility for designing energy efficient buildings had been ceded exclusively to the specialist engineering profession, new requirements are now forcing the technical spotlight back on to the architect, therefore reversing a tendency where architectural practice had been biased towards formal stylish design rather than to effectively address the challenges presented by environmental sustainability (Altomonte, 2008).

Most professional firms nowadays claim sustainable design as a key element of their approach to architecture. However, only few buildings recently produced have lived up to these claims, especially in relation to energy efficiency. Conversely, not many buildings hailed for environmental excellence have impressed architecturally, whereas carbon neutrality and reduction of consumptions have, more often than not, been prioritised over creative design, quality of life and psycho-physiological comfort of occupants, thus hindering the architectural value of the buildings being produced. With relatively few exceptions, a general lack of integrated technical skills amongst architects has manifested itself in a profession largely ill-equipped to handle the substantial paradigm shift involved in environmentally-responsible design.

This is epitomised primarily by the ambiguous nomenclature of terms such as 'sustainable', 'bioclimatic', 'ecological', 'green', 'eco-friendly' or 'environmental', which are recurring labels that, although rarely ascribed a precise meaning, are repeatedly and undistinguishedly attached to buildings in architectural competitions, magazines and debates, increasing confusion and misconceptions.

Indeed, the much abused term 'sustainability' has to go beyond the natural environment alone, satisfying the tangible and intangible needs for economic prosperity and social harmony through the complex interplay of a number of diverse dimensions. The need for sustainable development has, in fact, to concurrently embrace many different aspects of human activity, which include economic, socio-cultural, ethical and aesthetic values in addition to the environmental and technical issues surrounding energy consumption, management of resources and reduction of $\mathrm{CO}_{2}$ emissions that can ensure that tomorrow's generations will be able to satisfy their needs at the same level of today (WCED, 1997). To effectively promote sustainability in the design of the built environment, it is hence essential that technical principles and environmental targets are embraced within an adequate and creative design process, which is, without doubt, a prerogative of the architectural profession (Orr, 2002).

As a matter of fact, architecture is by its own definition the product of a creative process, which measures its success by its capacity to provide an answer to economic, aesthetic, ethical, socio-cultural and physio-psychological human needs. To promote sustainable design in the built environment, architecture must therefore assume a further dimension, conscientiously responding to the context where it is built and to the environment as a whole (Olgyay, 1963).

Design constraints are normally a stimulus to strive for more creative solutions. As a consequence, drawing on the recommendation to tap 'the power of limits' (Stokes, 2006), the requirement to meet technical and environmental targets can constitute inspiring design constraints that have in themselves the potential to lead to a generation of novel architecturally significant - and thus 'sustainable' - buildings. Lawson likens the role of a designer to a juggler keeping a number of balls in the air simultaneously, and states that the process of architectural design requires the architect to maintain and resolve a number of parallel lines of thought (Lawson, 2006). As in the physics of light, only when all the different wavelengths of visible radiation are balanced, in the right amount and proportions, pure white light will be visible. Sustainable design can hence be compared to white light, as the result of a thorough and composed interplay between different dimensions and design considerations.

In summary, to endorse a comprehensive definition of sustainable development in building practice and safeguard the environment and its finite resources within the context of an ethically, culturally and socially valuable design process, it is fundamental that architecture is informed by an overarching approach the supports the combination of energy efficient measures together with the need to secure people's comfort and quality of life, consistently integrating environmental awareness, knowledge and technical skills within a creative design discourse (Graham, 2002).

Clearly, this is an approach that has to be embraced since the very early stages of development of a design and cannot be left as an after-thought once the main formal and technical features of a building have already been resolved by the architect. To facilitate this process, it is necessary that mandatory requirements of enhancing sustainable environmental design in the practice of architecture represent a core issue within the formation of professional competence and ethos of the practitioners, therefore challenging a radical change in the way in which the architect's progression toward the profession is sustained by educational methodologies and delivery of contents.

The comprehensive embracement of sustainability in building design is demanding a substantial revision of the training process that grants access to the architectural profession, starting from the curriculum in higher education up to the 
continuing professional development of practicing architects. To consistently inform this process, it is however primarily necessary to:

- Ascertain the existing state of play with respect to the level of technical and environmental awareness, knowledge and requirements within architectural practices;

- Relate such demands to the pedagogical methods in use in higher education and architectural training with a view to converging on a series of criteria which can be proposed as the pedagogical basis for implementation within the architectural curriculum.

Such criteria will have to be fully embraced at the various stages of the curricular progression towards the practice of architecture and, most importantly, will have to be acknowledged by the institutional bodies that currently regulate access to the profession. Yet, some considerable barriers may need to be overcome to achieve this target.

\section{Accreditation and Qualification Criteria}

In the path towards preparing emerging practitioners for global practice, a potential obstacle to the comprehensive implementation of sustainable environmental design in architecture is represented by an apparent gap in the conditions for accreditation of higher education curricula and in the qualification criteria established by most professional bodies worldwide. This gap is most evident in the idiosyncrasies of an environment-related architectural education.

Across the world, there exist numerous prescription and validation criteria which control entry into the architectural profession. Indeed, these criteria are often inhomogeneous and characterised by loose requirements especially in ascertaining an effective balance and integration between creative and technical skills. Accreditation of educational programs in architecture and criteria for qualification of practitioners seek primarily to ensure that the standards attained by successful graduates of an architectural program are appropriate with respect to the design and professional ability and ethical formation required for competent practice. Obviously, the criteria in any accreditation/qualification policy should permit flexibility of approach and will - for reasons including cultural choice, tradition and so on - vary significantly from country to country. However, the weighting of the various criteria to be met for accreditation and qualification have to ensure adequate standards both in the educational system as in the professional practice.

The mission of all accreditation and qualification bodies - like the RIBA (Royal Institute of British Architects) and the ARB (Architects Registration Board) in United Kingdom - is generally to "advance architecture by demonstrating benefit to society and promoting excellence in the profession", and therefore "champion for architecture and for a better environment" (ARB/RIBA, 2002).

Nevertheless, although the objectives of the criteria established by professional bodies are almost unanimously to "develop professional education to respond to a changing environment", the emphasis often lies on the central generalist role of design, whilst technical and environmental knowledge is frequently assigned only a seemingly marginal role.

Although environmental targets are regularly mentioned within validation criteria (albeit at times in an ambiguous manner), there seem to be no measurable indicator for quantifying and qualifying these aspects of education, or a clear set of principles defining the level of environmental awareness, knowledge, understanding and skill that students must acquire at each stage of the process of qualifying as architects and/or building practitioners. Consequently, since environmental validation criteria are often not explicitly or specifically described - and remain thus open to interpretation - in general they cannot be considered as systematically beneficial to protecting a sustainable future in building design.

This lack of quantifiable measures assumes a further relevance especially in Europe in cognisance of the EC Directive 2005/36 on the mutual recognition of professional qualifications within European Member States, which in 2007 replaced the previous regulation (European Commission, 2006). A number of changes have been introduced by this Directive, including greater liberalisation of the provision of services, more automatic recognition of qualifications on the basis of common platforms and increased flexibility. Specifically, concerning the practice of architecture, the EC 2005/36 states:

"Architectural design, the quality of buildings, their harmonious incorporation into their surroundings, respect for natural and urban landscape and for the public and private heritage are a matter of public interest. Mutual recognition of qualification should therefore be based on qualitative and quantitative criteria which ensure that the holders of recognised qualifications are in a position to understand and translate the needs of individuals, social groups and authorities as regards spatial planning, the design, organisation and realisation of structures, conservation and the exploitation of the architectural heritage, and protection of natural balances." (Art. 27, 2005/36/EC)

It is important to point out that, in this legislative act, the only criteria that embrace a clear approach towards environmentally responsible design reiterate the need to understand "the relationship between people and buildings, and between buildings and their environment, and the need to relate buildings and the spaces between them to human needs 
and scale" (Section 8 - 'Architect', Article 46 - 'Training of Architect', point 'e') and the requirement for practitioners to have "adequate knowledge of physical problems and technologies and of the function of buildings so as to provide them with internal conditions of comfort and protection against the climate" (Section 8 - 'Architect', Article 46 'Training of Architect', point 'i') (European Commission, 2006).

So, although qualitative and quantitative criteria are mentioned in the EC Directive 2005/36 to achieve conditions for qualification of building practitioners and a balance between aesthetic and technical requirements is deemed necessary, no explicit direction is given concerning the integration of environmentally sustainable principles in building design. In essence, as far as qualification criteria are concerned, the EC 2005/36 simply repeats the prescriptive principles already listed in the Architects' Directive of 1985, the fundamental regulation that for 22 years had provided the basis for the recognition of architectural qualifications within the Member States of the European Union (European Council, 1985). Undeniably, the priorities behind the environmental agenda have changed considerably over the past two decades, therefore a substantial revision of these criteria must be addressed.

A global enquiry actually reveals that the implementation of sustainable environmental design in the curriculum of architects and in the conditions that regulate access to the profession is a theme which sits at the core of the activities of many academic and professional bodies and association of educators and practitioners (Stevenson, et al., 2009).

In the United States of America, for example, the American Institute of Architects is at present "seeking to inject ecological literacy and sustainability principles into architecture education" (AIA, 2006). It is also worth noting that, in the USA, sustainability has been added since 2004 to the "Conditions for Accreditation for Professional Degree Programs in Architecture', with a particular emphasis on the "understanding of the principles of sustainability in making architecture and urban design decisions and in the creation of healthful buildings" (NAAB, 2004). The US Educators Practitioners Network is also closely working with the Society of Building Science Educators, the AIA Committee on the Environment, and the AIA Sustainability Discussion Group to generate a Carbon Neutral Design Resource for educators and professionals (Boake, 2008). This resource will provide invaluable practical guidelines that will support the process of design and planning of carbon-neutral projects, including case studies that illustrate successfully constructed buildings and an extensive bibliography of available software and tools (Wasley, 2007).

Concurrently, in the United Kingdom, to address current pedagogical and professional challenges and facilitate discussion between academics, designers and representatives from qualification bodies, in 2008 the 'Designs on the Planet' workshop series was set up as a forum by Oxford Brookes University, the University of Nottingham and Cardiff University, with the primary aim of contributing to the development of environmental responsibility as a creative factor in the practice and pedagogy of architecture (Stevenson, et al., 2009). The workshop series was sponsored by the Centre for Education in the Built Environment (CEBE) and supported by the Royal Institute of British Architects (RIBA), which is at present working with the UK Architects Registration Board (ARB) to review existing criteria for qualification so as to meet contemporary professional demands and legislative requirements (e.g. the Code for Sustainable Homes, DCLG, 2007).

In consideration of these endeavours, it is clear that there is a global request for novel qualification criteria that regulate access to the profession and can nurture the fundamental importance of sustainability and an environmentally-responsible approach to design in the training and practice of architecture. To thoroughly embrace this challenge, it is however needed that combined efforts aim to:

- Normalize differences between learning outcomes of academic curricula and prescriptions for qualification of professionals, reiterating the fundamental role of sustainability and environmental thinking in the training and practice of building design;

- Propose a set of unambiguous measures for establishing quantitatively and qualitatively the knowledge of sustainable environmental design that is required at each level of progression towards the profession, for these to be consistently provided by pedagogies offered in academic curricula.

Yet, in consideration of current educational methods and curricular structures, meeting these challenges might have to surmount significantly impending difficulties.

\section{Architectural Curricula in Higher Education}

Environmentally responsive design and energy efficiency in buildings have been taught at many schools of architecture all over the world for many years. However, most such programmes have run in parallel to, and often in competition with, more mainstream options. For years, architectural education has been slow to respond to a new set of requirements, tending to assume the general view that the environmental aspects of buildings were the role of the engineering profession. It is only very recently that the perception of environmental design and energy efficiency has shifted from specialist technical concern to a more relevant position on the agenda of architectural education. However, while this is appreciable, this change of perception has not yet been consistently matched by a pedagogy fully embedding sustainable environmental design at the core of the architectural curriculum. 
An international enquiry into architectural education reveals that the achievement of a truly design-oriented integrated 'sustainable' curriculum is one that still proves elusive, compounded by the nature of the subject itself. As a matter of fact, contemporary architectural education has changed little over the last decades, whereas almost every school of architecture still makes a basic curricular split between theoretical and applied teaching units (Rutherford and Wilson, 2006). Specialist knowledge is generally delivered in satellite ex-cathedra lectures, with studio serving as the forum for synthesising the ideas, concepts and skills introduced into coherent design. In the lectures, it is assumed that students will learn the general principles and fundamental bodies of knowledge, which will then, in the studio, guide and inform all aspects of the design to respond to an assigned brief (Gelernter, 1988).

Invariably, however, lecture courses are often fragmented and alienated (physically and temporally) to applied coursework so that students are not able to fully engage with an integrated design process. Although apparently delivering the targeted learning outcomes, in reality this naive and misleading conception of how knowledge is acquired and applied only holds the result of increasing the remoteness between creative inspiration in design and acquisition of technical knowledge. In addition, more often than not, design studio projects are complex and time-demanding, to the extent that students are not able, in the temporal span of a semester, to achieve a mature and in-depth level of analysis which includes awareness and comprehensive implementation in design of technical and environmental mandates (Kock, et al., 2002).

Further to this, the emphasis currently given to an active-learning studio-based tutorial environment in most of the cases intensifies the struggle to reconcile creative design work and technical analysis and verification, since the mentioned cognitive discrepancies are not only related to students but also to their studio tutors, who are seldom proficient in the technical aspects of environmental design, whilst academic personnel teaching the technical subjects is often not associated with the design studio team. The experience of many architectural educators would support the view that by employing this pedagogy, technical knowledge is rarely integrated in any meaningful manner within design studio, this being a perennial problem that has taxed architectural educationalists for some time (Schon, 1984).

Research shows that architects generally employ a solution-focused rather than a problem-focused strategy in the development of design (Rutherford and Wilson, 2006). This cognitive style probably derives from educational practices where architectural students learn through a series of different design exercises and receive a criticism which is mostly focused on the solution they put forward rather than the methodology they apply. More often, students are not inherently asked to analyse a specific problem, but instead are required to propose a solution, thus focusing more on the achievement of a desired result rather than to a critical investigation of the complexity of the problem they face.

This cognitive style obviously hinders the development of critical thinking and personal development amongst students, and - in the best cases - only favours the mere (albeit often short-lived) acquirement of information. Conversely, to guarantee effective learning, a process of knowledge construction should be put in place "through active engagement, participation, and collaboration between learners and educators" (Datta, 2007).

The generalist nature of the architectural curriculum covers an extremely broad range of technical and non-technical areas, seeking to equip students with the awareness, knowledge, understanding and ability needed to perfect their design skills whilst making informed decisions in response to project briefs. Due to the complexity of the problem at hand, there can obviously be a plurality of approaches that could be adopted to address sustainable design in architecture, making it difficult to formulate any changes in the curriculum unless these are directly responsive to the modes and cultures of the teaching involved (Guy and Moore, 2007). Kolb's (1984) experiential learning theory identifies four different types of abilities that could support the successful achievement of effective deep learning and development of critical thinking: concrete experience, reflective observation, abstract conceptualisation, and active experimentation. And, as Warburton (2003) suggests, due to its inherent interdisciplinary nature, the achievement of effective deep learning becomes particularly important in the case of education for sustainability, since in this case holistic insight and the ability to organise and structure disparate types of information and knowledge into a coherent creative design whole is central to the achievement of the targeted pedagogical objectives.

A critical awareness of key concepts and the scope, limitations and complementarity of interdisciplinary paradigms are therefore primary aims of education for sustainability (Warburton, 2003). However, the achievement of such aims requires that the students engage in comparative and synthetic thinking at diverse levels, combining 'bottom-up' and 'top-down' approaches to a specific envisaged design solution. Students should also be encouraged to emphasise reflection and critical self-evaluation in order to take full ownership of the challenges involved in balancing design integrity with environmental responsibility. Conversely, in current pedagogies, environmental design is still often viewed as a mere positive addition to a successful scheme rather than a basic, essential and integrated requirement (and valuable input) of the design exercise itself. Clearly, in cognisance of contemporary challenges, this attitude is no longer acceptable and there is substantial pressure to re-evaluate the priorities that sit at the core of the architectural education.

It seems obvious therefore that to ensure that deep environmental competence is integrated with creative skills of students, a new interdisciplinary educational program that supports effective, deep learning and knowledge transfer is 
required to bridge the 'historic' divide between the disparate and often conflicting domains of the technical lecture and the imaginative studio. Such a program should equip graduates of architecture with a meaningful level of environmental competence, where technical knowledge is synthesised within studio, i.e. the natural forum for creative exploration of design solutions. Evidently, this challenge requires an intrinsic restructuring of most of the existing educational practices, and achieving a balance will pose several interesting challenges, whereas the implications of sustainability should be widely shared by both students and educators, in the environmental laboratory / lecture theatre as in the design studio.

As Yannas (2005) suggest, a good theoretical background is an essential requirement to provide students with the ability of translating physical laws in creative architectural forms. This, however, has to be supported by empirical knowledge and evidence-based learning so as to understand how different principles can be applied into practice, and by analytical tools and simulation techniques that can facilitate the testing and comparison of different hypotheses and make performance predictions starting from the early stages of design. These three cognitive domains have to be thoroughly delivered in architectural curricula without marginalising them in the form of technical or specialist studies.

Amongst existing opportunities, a way to leave room for self-reflection, deep learning and cultural understanding whilst combining theoretical knowledge, empirical skills and analytical tools - may be, as an example, given by employing new advanced educational techniques derived from information technology. In this context, the use of e-learning pedagogies and methodologies is an area that is rapidly becoming core to many teaching and learning institutions worldwide, in the effort to enhance their educational provision and meet current professional demands (Mizban and Roberts, 2008).

The applications of e-learning in fields such as medicine, engineering, computer-aided design and manufacturing have actually proven it to provide the necessary learning environment to facilitate multi- and inter-disciplinary collaboration between specialists in distinct areas, skills that are fundamental to the achievement of an integrated design process. Similarly, it can be argued that its popularity in both primary and secondary education is a proof to the confidence that educationalists are placing on its effectiveness in meeting the learning outcomes associated with the various key stages of these curricula. It is undeniable therefore that through such inspiring examples, e-learning holds the potential to provide a breakthrough in interdisciplinary integration also within architectural education, and mark a significant step forward in blending creativity with practical skills within the profession as a whole. In the same way, it is obvious that the architecture students of today would expect that such ICT methodologies and technologies are employed in their teaching and learning due to their exposure to these systems throughout their education pathway and in the professional environment.

In essence, it is evident that there still exist a number of pedagogical barriers that hinder education for sustainability to be consistently endorsed in current architectural curricula. Nevertheless - drawing from cognate disciplines and exploring inter-, intra- and extra-disciplinary contributions to improved pedagogical methods - there also exist some potentially groundbreaking opportunities for the technical material associated with sustainable design to move beyond the final line of the calculation and converge in a more central position on the agenda of architectural education.

A collaborative approach to the delivery and assessment of an environment-related design programme must therefore be embraced, this representing a substantial departure from existing curricular structures. Yet, if the development of an educational methodology for the enhancement of sustainable environmental design in university curricula proves successful, graduates of the near future could significantly contribute towards improving the energy performance of new and existing buildings and, ultimately, contributing to meeting global challenges within the realms of a creative design process.

\section{The EDUCATE Action}

\subsection{The Mission of EDUCATE}

To overcome the pedagogical and professional barriers that currently hinder the implementation of sustainable environmental design in the education and practice of architecture, the EDUCATE Action (Environmental Design in University Curricula and Architectural Training in Europe) - funded by the European Commission - has been built on a consortium of seven European academic partners: the University of Nottingham (UK, Coordinator); the Architectural Association School of Architecture (UK); the Catholic University of Louvain (Belgium); the Technical University of Munich (Germany); the Department ITACA, University of Rome La Sapienza (Italy); the Seminar of Architecture and Environment (Spain); and the Budapest University of Technology and Economics (Hungary) (Note 1).

The Action - started in June 2009 - has also received the support of all the Chambers of Architects in the six participating countries, of internationally renowned building professionals in the field of sustainable architecture, of experts of cognate disciplines (e.g. education, engineering, information technology, ecology, etc.) and of associations of educators and practitioners, which will support the consortium in fostering the integration of sustainable environmental design in architectural education and practice and propose the harmonisation of academic curricula as well as of the 
criteria and conditions for accreditation and professional qualification across European Member States.

The mission of EDUCATE is to "foster knowledge and skills in sustainable environmental design aiming to achieve comfort, delight, well-being and energy efficiency in new and existing buildings. This will be promoted and demonstrated within a culturally, economically and socially viable design process, at all stages of architectural education" (EDUCATE, 2009).

To these aims, EDUCATE is set to achieve the following objectives:

- Remove pedagogical barriers to the integration of environmental design principles within a creative architectural discourse;

- Define and test a curriculum and pedagogical framework which bridges current divides between sustainability-related technical information and the design studio at different levels and stages of architectural education to meet current professional demands and expectations;

- Develop an intelligent portal on sustainable environmental design that facilitates such integration in higher education and supports continuing professional development for building practitioners;

- In concert with Chambers of Architects, propose homogeneous criteria for accreditation of architectural curricula and professional registration that clearly establish the level of awareness, knowledge, understanding and skill in sustainable environmental design expected of graduates qualifying as architects;

- Promote and disseminate environmental know-how and exempla of best practice amongst students, educators, building professionals and the public, fostering change of behaviour and expectations towards the integration of sustainable design in architecture (EDUCATE, 2008).

\subsection{Research Methodology}

Throughout the 36 months of its duration, the EDUCATE Action will build on existing synergies and intra/inter-university programmes in place at participating institutions and draw from parallel experiences currently undertaken worldwide.

The Action will primarily analyse and consolidate the international state-of the-art of curricular structures and professional requirements at a European and global level. To this aim, the partners will conduct an exhaustive analysis of the state of play in terms of environmental education at university level (including curricular contents and structure, course syllabuses, delivery methods, assessment criteria, etc.), and will investigate how these relate to the conditions for accreditation of academic curricula and requirements for professional qualification as established by competent bodies in the various country considered. This task will include a general overview of education literature and a comparison of the state-of-the art with contemporary theories/practice. In addition, partners will ascertain (via specifically designed surveys) the level of awareness, knowledge, ability-base and requirements of environmental design within the practice of architecture, so as to identify strengths and weaknesses of various pedagogical methods, extrapolate exempla of best practice and define an agenda for sustainable architectural education that consistently responds to the demand of enhancing environmental design in buildings and therefore contributes towards a sustainable built environment.

Throughout the second phase of the Action, the work will concentrate on the development of a pedagogical framework and curricular structure enabling the adoption and incorporation of the principles and practice of environmentally sustainable design at the different levels and stages of architectural education. Basing on the outcomes previously obtained, inter-, intra- and extra-disciplinary contributions to a restructured pedagogy will be explored (also drawing from seemingly distant disciplines such as engineering, aeronautics, medicine, computer science, etc.), together with the appraisal of applied/experiential learning, new analytic visualisation tools and the integration of up-to-date technical and didactic insights from pedagogical research. In this task, partners will be assisted by specialists in educational science in order to facilitate the definition of curricular methodologies that foster knowledge transfer between technical and creative domains.

Concurrently, in collaboration with professional bodies, building practitioners and associations of educators, partners will benchmark the needs and expectations of the market and identify pedagogical objectives and technical knowledge of environmentally sustainable design to be embedded at the different stages of the training of architects. Combining these activities with the creation of a broad knowledge-base on environmental design, the project will propose a curriculum enabling the successful incorporation of principles of sustainable design at every stage of progression towards professional qualification. The curriculum will be constructed in accordance with the Bologna structure of higher education (European Higher Education Area, 1999), thus embedding relevant principles and practice of sustainable design across 6 years of architectural education (3 years undergraduate, 2 years graduate, 1 year postgraduate) and within continuing professional development (CPD). Whilst providing homogenous criteria for measuring the learning outcomes on a scale that encompasses both conventional architectural principles and those of environmental performance, the curriculum will be based on a pedagogical framework that will allow sufficient 
flexibility for it to be adapted to a diversity of contexts, backgrounds, educational systems, teaching approaches and environmental targets.

The outcomes of this phase of the work will be trialled across participating institutions during the subsequent stage of the Action, in order to test the pedagogy devised and measure its success in terms of incorporation of environmental sustainability within a creative architectural discourse. Partners will exploit the development of an interactive portal on sustainable environmental design in architecture to consolidate information and facilitate exchange of know-how and remote collaboration amongst staff and students, whilst external professionals will be involved in interactive education. At the conclusion of the testing phase, the final results will be evaluated by an Advisory Board composed by representatives of professional bodies and internationally renowned architects in the field of sustainable environmental design, which will contribute to validate the pedagogical outcomes achieved and measure the success of the proposed curriculum in effectively embedding principles and practices of environmental sustainability within creative design.

The results obtained will inform the following activities in terms of formulation of principles for sustainable architectural education and proposition of professional qualification criteria. In this phase, the partners will appraise and validate the results obtained during the testing of the curriculum in terms of learning outcomes and achieved educational objectives. In addition, the Action will acknowledge feedback from relevant key actors and target groups in order to improve and refine the pedagogical framework proposed. The developed pedagogy will be compared with the state-of-the-art of higher education so as to facilitate adaptation of the curriculum to respond to different backgrounds, cultural contexts, teaching approaches and environmental targets and will be consolidated in the production of a final document that will be disseminated to educators and academic institutions at a European and global level. Concurrently, a set of conditions for accreditation of academic curricula and criteria for professional registration to be implemented by regulatory bodies will be proposed. The tasks will initially consist in ascertaining the level of technical competence acquired by students and graduates under the proposed curricular structure and compare it against current criteria for professional qualification. Therefore, a series of guidelines establishing the level of knowledge and ability in environmentally sustainable design expected of graduates at every level of their education will be formulated. These criteria will have a prescriptive nature, but will still allow some flexibility for them to be potentially embraced by regulatory bodies in different countries.

Throughout the project, EDUCATE will engage academics, practitioners, representatives of industry and professional bodies, as well as the general public, in a series of workshops and symposia that will be organised to reach target groups, disseminate exempla of best practice and sustainable environmental know-how, and encourage change of behaviour and demands towards the intelligent integration of environmental principles in the conception, construction and operation of buildings.

\subsection{Result Indicators and Expected Outcomes}

Building on the existing state of play of environmental awareness, knowledge and ability-base in architectural education and practice, EDUCATE is set to provide an effective platform for implementing environmental design as a creative factor in the practice of architecture with significant impacts, in the short and long term, on the sustainability of the built environment. To measure the success of the proposed research methodology, the main indicators will consist in:

- Learning outcomes of architecture students as incorporating environmental principles in building design. This indicator will be measured on the analysis of trends in students' grades in design subjects that integrate environmental/energy-related taught modules; increase of students' satisfaction on the architectural curriculum (e.g. students evaluation of teaching); and feedback from academics, practitioners, external examiners and validation authorities concerning the implementation of the curriculum and the results of the testing at participating institutions.

- Adoption of the proposed pedagogical framework, curricular structure and qualification criteria by academic institutions and professional bodies. This will contribute to deconstruct the pedagogical barriers to the effective integration of sustainable environmental design in higher education and in the practice of architecture, and will fill a 'gap' in current accreditation and registration prescriptions as reflected in the loose requirements of most regulatory bodies concerning the implementation of energy-related environmental principles in the training of professionals.

- Dissemination of understanding, knowledge and skills of sustainable environmental design amongst students, educators, practitioners and the general public. In the long term, this will be measured by an expected increase in awareness of environmentally sustainable design by architects and change in behaviour by the public (e.g. clients, homeowners), with measurable impacts on the achievement of targeted environmental objectives at a local and global level, in terms of energy efficiency, $\mathrm{CO}_{2}$ emissions and management of resources. 


\section{Concluding Remarks}

To respond to the challenges of the current climate crisis and guarantee a sustainable future to human settlements, the marketplace nowadays demands graduates of architectural disciplines able to face a range of integrated problems which include, other than abilities in creative design, also competence of environmental issues. For this to take place, a comprehensive process of revision of higher education and professional development is needed, so as to guarantee that the promotion of sustainable environmental design sits at the core of the curriculum towards the practice of architecture.

A number of potential pedagogical and professional barriers can hinder the successful implementation of such process, although also several opportunities can foster the attainment of the targeted objectives. Efforts and initiatives promoted by educational and professional bodies at a global level testify the growing appreciation of the need to break out of conventional academic and curricular disciplinary compartments and bridge divides between creative arts and technical sciences, theory and practice, and learning in academic and non-academic environments.

This is leading to a new focus upon the notion of integrated and deep learning, which, supporting the emphasis on the collaboration between disparate disciplines, can reiterate the need for a holistic approach in the pedagogy and training of building professionals, where design is not only seen as a creative problem-solving exercise but where analytic skills, cross-referencing, imaginative reconstruction and independent thinking can form the basis of a restructured architectural culture fostering meaningful dialogue across seemingly distant fields of knowledge and specialised expertise.

The promotion of deeper and more integrated architectural education that cultivates not only students' creative approach but also interconnected understanding of subjects and disciplines, self- and other-awareness combined to purposeful, ethical action is to be promoted. It is hoped that initiatives such as the European EDUCATE Action will give a contribution towards the achievement of such educational goals and reiterate the role that 'technical' environmental inputs can have on the overall quality of design, reinforcing their role as truly creative factors in the practice of architecture.

\section{Acknowledgments}

The EDUCATE Action is funded by the European Agency for Competitiveness and Innovation (EACI) of the European Commission, under the 'Intelligent Energy Europe' Programme 2008. The author heartily acknowledges the support and contribution given by the EDUCATE partners to the definition of the framework, objectives and work programme of the Action, and the contents of this paper.

\section{References}

AIA American Institute of Architects. (2006). Ecological Literacy in Architecture Education. COTE Report and Proposal: AIA.

Altomonte, S. (2008). Climate Change and Architecture: Mitigation and Adaptation Strategies for a Sustainable Development. Journal of Sustainable Development, 1(1): 98-114.

ARB/RIBA. (2002). Prescriptions of Qualification. London: Architects Registration Board.

Boake, T.M., et al. (2008). Carbon Neutral Design Project. [Online] Available: http://www. sparksdesigns.co.uk/workingfiles/bluezulu/oxfordconference/presentations/pdfs/01_3_2.pdf (October 10, 2009)

Datta, A. (2007). Gender and Learning in the Design Studio. Journal for Education in the Built Environment, 2(2), 21-35.

DCLG, Department for Communities and Local Government. (2007). Building a Greener Future: policy statement: Towards Zero Carbon Development. London: Crown.

EDUCATE. (2009). Environmental Design in University Curricula and Architectural Training in Europe. Description of the Action and Work Programme.

EDUCATE. (2009). Mission Statement. Action Kick-off Meeting, Nottingham, 7th July 2009.

European Commission. (2003). Directive 2002/91/EC of the European Parliament and of the Council of 16 December 2002 on the Energy Performance of Buildings. Official Journal of the European Union, 4 January 2003.

European Commission. (2006). Directive 2005/36/EC of the European Parliament and of the Council of 7 September 2005 on the Recognition of Professional Qualifications. Official Journal of the European Union, 30 September 2005.

European Council. (1985). Council Directive 85/384/EEC of 10 June 1985 on the mutual recognition of diplomas, certificates and other evidence of formal qualifications in architecture, including measures to facilitate the effective exercise of the right of establishment and freedom to provide services. Official Journal of the European Union, 21 August 1985.

European Higher Education Area. (1999). The Bologna Declaration of 19 June 1999. Joint declaration of the European Ministers of Education. [Online] Available: http://www.esib.org/index.php 
/documents/external-documents/426-bologna-process-documents (October 21, 2009)

Gelernter, M. (1988). Reconciling Lectures and Studio. Journal of Architectural Education, 41(2), 46-52.

Graham, P. (2002). Building Ecology: First Principles for a Sustainable Built Environment. Oxford: Wiley Blackwell.

Guy, S., Moore, S.A. (2007). Sustainable Architecture and the Pluralist Imagination. Journal of Architectural Education, 60(4), 15-23.

IPCC. (2007a). Climate Change 2007: The Physical Science Basis. Contribution of Working Group I to the Fourth Assessment Report of the Intergovernmental Panel on Climate Change [S. Solomon, D. Qin, M. Manning, Z. Chen, M. Marquis, K.B. Averyt, M. Tignor and H.L. Miller (Eds.)]. Cambridge: Cambridge University Press.

IPCC. (2007b). Climate Change 2007: Impacts, Adaptation and Vulnerability. Contribution of Working Group II to the Fourth Assessment Report of the Intergovernmental Panel on Climate Change [M.L. Parry, O.F. Canziani, J.P. Palutikof, P.J. van der Linden and C.E. Hanson (Eds.)]. Cambridge: Cambridge University Press.

IPCC. (2007c). Climate Change 2007: Mitigation. Contribution of Working Group III to the Fourth Assessment Report of the Intergovernmental Panel on Climate Change [B. Metz, O.R. Davidson, P.R. Bosch, R. Dave and L.A. Meyer (Eds.)]. Cambridge: Cambridge University Press.

Kock, A., Schwennsen, K., Dutton T.A., Smith, D. (2002). The Redesign of Studio Culture. A Report of the AIAS Studio Culture Force. Washington: AIAS-American Institute of Architecture Students.

Kolb, D.A. (1984). Experiential Learning: experience as the source of learning and development. New Jersey: Prentice-Hall

Lawson, B. (2006). How designers think: The design process demystified. London: Architectural Press.

Mizban, N., Roberts, A. (2008). A Review of Experiences of the Implementation of E-learning in Architectural Design Education. CEBE Working Paper, 13.

NAAB National Architectural Accrediting Board. (2004). NAAB Conditions for Accreditation for Professional Degree Programs in Architecture. New York: AIA.

Olgyay, V. (1963). Design with climate: bioclimatic approach to architectural regionalism. Princeton: Princeton University Press.

Orr, D. W. (2002). The Nature of Design: Ecology, Culture and Human Intention. New York: Oxford University Press.

Rutherford, P., Wilson, R. (2006). Educating environmental awareness: creativity in integrated environmental design teaching. In Shannon, S., Soebarto, V., Williamson, T., (Eds.) Challenges for architectural science in changing climates: Proceedings of the 40th annual conference of the Architectural Science Association ANZASCA. Adelaide: School of Architecture.

Schon, D.A. (1984). The Architectural Studio as an Exemplar of Education for Reflection-in-Action. Journal of Architectural Education, 38 (1), 2-9.

Stevenson, F., Roberts, A., Altomonte, S. (2009). Designs on the Planet. A workshop series on architectural education and the challenges of climate change. In PLEA Passive Low Energy Architecture Conference 2009, 22-24 June 2009, Quebec, Canada.

Stokes, P. (2006). Creativity from Constraints: The psychology of breakthrough. New York: Springer.

Warburton, K. (2003). Deep learning and education for sustainability. International Journal of Sustainability in Higher Education, 4 (1), 44-56.

Wasley, J. (2007). The SBSE Wingspan Conference on the Carbon Neutral Design Studio. [Online] Available: http://www4.uwm.edu/cds/PDF/researchInitiatives/WasleyWingspreadCarbonNeutralStudio (October 10, 2009).

WCED World Commission on Environment and Development (1987). Our Common Future, Report of the World Commission on Environment and Development (Bruntland Report). Annex to General Assembly document A/42/427, Development and International Co-operation: Environment.

Yannas, S. (2005). Towards Environmentally Responsive Architecture. In PLEA Passive Low Energy Architecture Conference 2005, 13-16 November 2005, Beirut, Lebanon.

\section{Notes}

Note 1. Further information on the EDUCATE Action, news, events and related initiatives, are available on http://www.educate-sustainability.eu 